\title{
A cobertura da Covid-19 no Rio de Janeiro: aspectos da rotina produtiva do Telejornalismo Local
}

\section{Covid-19 coverage in Rio de Janeiro: aspects of the production routine of Local Newscast}

\author{
Cláudia Thomé \\ Universidade Federal de Juiz de Fora | Rua José Lourenço Kelmer, s/n - Juiz de Fora - MG | \\ Brasil | http://orcid.org/0000-0003-4759-3643| cthomereis@gmail.com \\ Edna de Mello Silva \\ Universidade Federal de São Paulo | Rua Sena Madureira, 1500, São Paulo - SP | Brasil | \\ http://orcid.org/0000-0003-1312-9041| prof.ednamello@gmail.com

\section{Marco Aurelio Reis} \\ Universidade Estácio de Sá | Rua do Bispo, 67, Rio Comprido, Rio de Janeiro - RJ | Brasil \\ https://orcid.org/0000-0003-0710-6361 | mreis1968@gmail.com

\section{Ana Paula Goulart de Andrade} \\ Universidade Federal do Rio de Janeiro | Av. Pasteur, 250 - Urca, Rio de Janeiro - RJ | Brasil | \\ http://orcid.org/0000-0003-0414-1305 | goulartdeandrade@gmail.com
}

Fechas | Recepción: 16/01/2021 I Aceptación: 28/02/2021

\section{Resumo}

O telejornal brasileiro passou por uma série de mudanças diante dos desafios da cobertura durante a pandemia Covid-19, com alteração das rotinas produtivas, demanda por novos papéis e competências profissionais e novas produções de sentido nas telas. Mudanças na anatomia do telejornal (Piccinin \& Soster, 2012) marcam fases, que também incluem a construção narrativa que vinha sendo feita sobre a própria pandemia em todos os momentos. O objetivo deste artigo é apresentar uma análise da cobertura da pandemia em 18 edições dos telejornais RJ1 e RJ2, veiculados no estado do Rio pela Rede Globo. A metodologia adotada foi a de estudo de caso (Yin, 2011), nos primeiros nove meses de cobertura da Covid-19, tendo como referencial teórico as fases do telejornal

\section{Abstract}

Brazilian newscasts have experienced a series of changes in face of the challenges of Covid-19 coverage, with changes in production routines, demand for new functions and skills, and new productions of meaning on screens. The change in the anatomy of the newscast (Piccinin \& Soster, 2012) went through phases, which also include the narrative construction that was being made about the pandemic itself at all times. The purpose of this article is to present an analysis of the pandemic coverage in 18 editions of the RJ1 and RJ2 newscasts, broadcast by Rede Globo in Rio de Janeiro. The method that was used is the Case Study (Yin, 2011), aplied in the first nine months of Covid19 coverage, using as theorical reference the phases of Brazilian television news programs detected by Silva (2018). The aim is to identify 
brasileiro detectadas por Silva (2018). Buscamos aqui identificar novas estratégias narrativas (Thomé \& Reis, 2019a), observando características de fases anteriores que foram retomadas e/ou ressignificadas, e também como a pandemia alterou rotinas produtivas e gerou novas produções de sentido nas telas. Fontes de informação com microfone em mãos, imagens enviados por aplicativos, repórteres com máscaras em coberturas externas, imagens de arquivo ressignificadas e predomínio de contribuições de repórteres "ao vivo". As mudanças na anatomia do telejornal (Piccinin \& Soster, 2012) passaram por fases, que incluem também a construção narrativa que se fazia sobre a pandemia em cada momento da cobertura televisiva analisada.

Palavras-chave: Covid-19, telejornalismo, Rio de Janeiro, adaptação, novas rotinas. the new narrative strategies (Thomé \& Reis, 2019a), observing what characteristics of previous phases were retaken and / or reformulated, and also how the pandemic changed productive routines and generated new productions of meaning on the screens. Sources holding microphone, sounds sent by applications, reporters with masks, resignified archive images and predominance of live broadcast - the change in the anatomy of the newscast (Piccinin \& Soster, 2012) went through phases, which also included the narrative of construction being done on the pandemic itself at each time of newscast coverage that was analiysed.

Keywords: Covid-19, telejournalism, Rio de Janeiro, adaptation, new routines.

\section{INTRODUÇÃO}

O presente artigo traz resultados de pesquisa sobre o telejornalismo brasileiro frente à pandemia, com foco na cobertura regional feita no Rio de Janeiro pelas equipes dos telejornais regionais RJ1 e RJ2, veiculados pela Rede Globo, emissora hegemônica no país, nos termos de Bolaño e Melo (2015) e com audiência do telejornalismo $220 \%$ maior que a segunda colocada ${ }^{1}$. A análise das alterações no fazer telejornalístico de março a setembro de 2020 exige que a pesquisa olhe pelo retrovisor do que já vinha sendo estudado em transformações no campo e nas alterações na construção narrativa do telejornalismo brasileiro ao longo do tempo. Não se pode observar os primeiros nove meses de cobertura da pandemia sem considerar as sete décadas de história do telejornalismo brasileiro.

A pesquisa, da qual resulta o presente artigo, ancora-se em estudos referenciais sobre as mudanças no telejornalismo ao longo do tempo, que são fundamentais para compreensão sobre o que mudou na cobertura em função da Pandemia Covid-19. O objetivo é compreender o complexo momento do telejornalismo brasileiro, em geral, e do regional, em particular, de modo a contribuir para a história e o ensino do telejornalismo no Brasil. Busca-se detectar momentos de virada no modo de produção, identificando fases do noticiário na pandemia, com a introdução e retomada de técnicas e formas de fazer, introduzindo a exigência de novas competências no telejornal. Tal análise foi feita a partir da metodologia de estudo de caso (Yin, 2011), por abarcar tanto a atuação do jornalista quanto o papel do telejornalismo no cotidiano da sociedade.

A trajetória do fazer telejornalístico vem sendo permeada e construída, de forma nada estática, pelas mudanças tecnológicas, pelos novos contextos comunicacionais, por alterações no modo de narrar, tendo como foco sempre sua função de informar. A função do telejornal se

\footnotetext{
${ }^{1}$ In https://www.kantaribopemedia.com/dados-de-audiencia-nas-15-pracas-regulares-com-base-noranking-consolidado-22-02-a-28-02-2021/. Acessado em: 07/03/2021
} 
manteve ao longo dos anos, mas a forma como construiu e como levou a notícia ao telespectador não foi a mesma sempre, variando a partir da tecnologia, da relação com o público, do que se entende por narrativa certificada a cada momento. Assim, considerando as soluções que o telejornalismo brasileiro foi apresentando frente aos desafios, às novas rotinas, ao desenvolvimento tecnológico e às formas de narrar, Silva (2018) detectou a existência de seis fases: telejornalismo falado, telejornalismo reportado, telejornalismo All News, telejornalismo convergente, telejornalismo expandido e telejornalismo imersivo.

Considerando alterações nas rotinas produtivas impostas pela pandemia do Covid-19, tais como uso de máscaras por repórteres nas coberturas externas e respeito ao isolamento social, a proposta do artigo é apresentar uma análise do telejornalismo local no Rio de Janeiro, em 18 edições do RJ1 e RJ2, tendo como referencial teórico as fases do telejornalismo detectadas por Silva (2018). Busca-se identificar as novas estratégias narrativas e em que medida características de fases anteriores do fazer telejornalístico foram retomadas e/ou ressignificadas durante a cobertura da Covid-19, além de apontar as mudanças nas rotinas produtivas, que demandaram novas funções e competências dos jornalistas.

\section{O TELEJORNALISMO BRASILEIRO EM FASES - CARACTERÍSTICAS E ESTRATÉGIAS}

Desde o início da pandemia, foram muitas as mudanças identificadas no noticiário televisivo brasileiro, com alteração também das rotinas produtivas. Tais rotinas demandaram novas funções e competências das equipes, além das que já vinham sendo exigidas anteriormente. 0 que se detecta, no entanto, é que as mudanças não foram todas incorporadas ao mesmo tempo. Houve um fluxo de inserção de alternativas no processo produtivo: home office, seguido de dois microfones (um para repórter e outro para entrevistado), e do uso de máscaras ${ }^{2}$ para repórteres em coberturas externas. Essas alterações citadas ficaram evidenciadas nas telas. Sonoras em aplicativos, seguidas de participação ao vivo de repórteres, também inauguraram novas formas e estruturas no noticiário.

Não há dúvida que a televisão e o jornalismo não possuem as mesmas práticas de 10, 20 ou 50 anos atrás. A todo momento surgem novos desafios, porém há vestígios de permanência nos conceitos e nas formas de como o meio encara a informação jornalística. Nesse sentido, é possível pensar que ao longo de sua trajetória o telejornalismo brasileiro tenha desenvolvido práticas, que foram internalizadas pelos profissionais de TV (jornalistas, técnicos, gestores) e disseminadas pelas escolas de jornalismo, nos estúdios e nas redações, que se constituem no que podemos chamar de um "saber telejornalístico". (Silva, 2018, pp.19-20)

Para analisar a cobertura telejornalística brasileira na pandemia, e entender o que mudou, é importante resgatar as fases anteriores e suas características antes da Covid-19. O "saber telejornalístico" foi sendo construído a partir das práticas construídas ao longo do tempo no telejornalismo, considerando, ainda, que as formas de narrar o "real" a cada momento

\footnotetext{
${ }^{2}$ Os telejornais regionais seguiram a medida anunciada no telejornal exibido em rede pela Globo, o Jornal Nacional, no dia 4 de maio de 2020, quando o apresentador e editor William Bonner anunciou e explicou o uso das máscaras pelas equipes de externas como forma de prevenção. In: https://g1.globo.com/jornal-nacional/noticia/2020/05/04/reporteres-da-globo-vao-passar-a-usarmascara-inclusive-diante-da-camera-nas-ruas.ghtml. Acessado em: 20/05/2020.
} 
também foram passando por mutações, e que a estratégia de certificação pode mudar a cada contexto (Thomé, Piccinin e Reis, 2020). As mudanças são sucessivas, mas tal saber vai sendo reelaborado, fazendo com que as práticas sejam retomadas ou mesmo ressignificadas e adaptadas em fases seguintes.

A primeira fase, categorizada por Silva (2018) como Telejornalismo Falado, remete à chegada da TV no Brasil, em 1950, em que o improviso foi uma importante marca nas produções televisivas e o telejornalismo herdou e incorporou a linguagem do jornalismo radiofônico. "As notícias eram apresentadas no formato de nota ao vivo (nota seca) e nota coberta (voz do locutor narrando as imagens)", afirma Silva (2015, p. 8). Havia uma centralidade do apresentador, já inaugurada no "Imagens do Dia", primeiro telejornal brasileiro.

Os tipos de enquadramentos valorizados entre as décadas de 50 até meados dos anos 60 para os apresentadores foram o primeiro plano e o close. Neste telejornal, em que o apuro técnico não supria todas as exigências com boas imagens dos acontecimentos, 0 apresentador ocupava um lugar de destaque no noticiário. Resguardadas as devidas proporções e limitações técnicas é algo bem parecido do que podemos encontrar ainda hoje em muitos telejornais. (Silva e Alves, 2017, p. 4)

O telejornalismo regional brasileiro se desenvolveu na segunda fase, identificada por Silva (2018) como Telejornalismo Reportado. A novidade nesse período fica por conta, sobretudo, da chegada do videoteipe, no fim dos anos 1950, que permitia a gravação de programas, iniciando um importante processo de mudança na rotina produtiva dos programas televisivos. No entanto, nas reportagens de televisão, não houve mudanças significativas em um primeiro momento, tendo em vista que os equipamentos ainda eram muito pesados, dificultando a mobilidade das equipes, o que mudou mais tarde, nos anos 1970, com as câmeras portáteis (Silva, 2018).

Na terceira fase, do Telejornalismo All News, Silva (2018) aponta a chegada da TV por assinatura, nos anos 1980, e a consequente inauguração de novos canais de notícias. Foi uma fase marcada pela instantaneidade da notícia, com transmissões ao vivo (stand ups). "Os canais de telejornalismo deram ao espectador a possibilidade de acompanhar mais de perto as notícias do dia, não ficando preso exclusivamente aos horários da grade de programação" (Silva, 2018, pp. 25-26).

A fase do Telejornalismo Convergente foi de profundas transformações, a partir das possibilidades que surgem com as tecnologias digitais. A edição não-linear foi "uma das grandes mudanças nas rotinas produtivas do jornalismo televisivo" (Silva, 2018, p. 26), que impactou em uma série de alterações no fazer telejornalístico brasileiro, incluindo a inserção de videografismos. A participação dos telespectadores com envio de imagens de flagrantes também se efetiva nesse período.

O transbordamento do telejornal para as redes sociais, em participações de repórteres e apresentadores em mídias sociais e aplicativos, configura o que Silva e Alves (2016) batizaram como Telejornalismo Expandido. É dessa fase, segundo Silva (2018, p. 29), a retirada da sigla TV dos nomes dos telejornais regionais da Rede Globo, mudando de RJTV, por exemplo, para 
RJ1 e RJ2, alteração que efetiva nas telas essa expansão do conteúdo e da relação com o telespectador. Por fim, há a sexta fase, identificada por Silva (2018) como Telejornalismo Imersivo, que usa tecnologias de realidade virtual, com vídeos em 360․

Das fases anteriores, observa-se que há rastros narrativos que permanecem na trajetória de forma ativa, como por exemplo o efeito do "ao vivo". Há outros que continuam mas ganham novas significações, como o improviso, que já pode ter sido associado a alguma precariedade, mas que pode representar também uma narrativa autêntica, sem edições, em uma estética, por exemplo, de imagens de flagrante ou produzidas por cinegrafistas amadores ou pelos próprios telespectadores. A função enunciativa ganha, então, novos contornos. As transmissões ao vivo, no telejornalismo, carregam o efeito de testemunho do fato, com potencial de gerar uma ideia de janela para um real pretensamente autêntico. "Assim, tem-se a sensação de ser testemunha do acontecimento, sem a mediação da TV, e não de acompanhar um recorte da realidade nas transmissões ao vivo" (Becker, 2016, p, 69).

No início da pandemia, ainda em março de 2020, as equipes dos telejornais regionais brasileiros fizeram revezamento, em situação de quarentena parcial, e houve participação de repórteres de dentro de suas casas. O ao vivo em home office trouxe para a cobertura um outro efeito, não de transmissão no local do fato, mas de abertura de espaços privados para dar as notícias mais recentes ao público. Nessa ação, identifica-se uma notícia subliminar, em uma ação pedagógica na construção narrativa do noticiário (Vizeu e Cerqueira, 2019b), pelo exemplo a ser seguido de isolamento social. Naquele momento, não eram as câmeras pesadas das primeiras fases que inviabilizavam a mobilidade das equipes, mas o risco de contaminação que reduzia as gravações externas, aumentando as participações ao vivo, algumas dentro da emissora também, e as edições intercalando as falas de âncoras, repórteres e fontes. Em relação à linguagem audiovisual, foram retomados os enquadramentos do close e do primeiro plano, (próprios da primeira fase do telejornalismo), adequados às dinâmicas imagéticas de celulares, tablets e câmeras DSLR utilizados para a captação das imagens no ambiente doméstico.

A gravidade do que estava sendo noticiado (e ainda está) também nem sempre foi a mesma na construção narrativa sobre a própria pandemia. A análise de 18 edições do RJ1 e RJ2 mostra que as fases da cobertura da Covid-19 seguem também pressupostos diferentes, a partir do que se tinha de conhecimento sobre o vírus e os riscos. Especialistas da área da saúde foram fontes frequentes nos telejornais e, de 17 de março e 22 de maio de 2020, a Rede Globo veiculou, em rede nacional, o programa "Combate ao coronavírus", que trazia informações científicas e tirava as dúvidas dos telespectadores.

O telejornalismo regional brasileiro já vinha espelhando as transformações das "cabeças de rede" das capitais, seguindo novas formas de produção e transmissão de notícias diante do avanço tecnológico do meio e das redes sociais digitais (Thomé e Reis, 2019b). Como afirmam Coutinho e Emerim (2019, p. 33), “essa experiência televisiva do local (...) é orientada pelas emissoras cabeças de rede, ou geradoras, não apenas quanto aos horários de exibição, mas também quanto a formatos, cenários, vinhetas de abertura e conteúdos". 


\section{TELEJORNALISMO REGIONAL NA PANDEMIA DA COVID-19 - NOVAS ROTINAS PRODUTIVAS}

Antes da pandemia, o telejornalismo brasileiro já vinha passando por transformações em função de novos contextos comunicacionais. Para o presente trabalho, estão considerados os estudos sobre o telejornalismo midiatizado (Piccinin e Soster, 2012), em que já vinham sendo observados elementos de atorização, dialogia, autorreferencialidade, sobre a reinvenção do telejornal (Becker, 2016) e sobre o lugar de referência do telejornalismo local (Vizeu e Cerqueira, 2019a).

Vale salientar que, a partir das rotinas produtivas profissionais e de uma série de critérios de noticiabilidade variáveis e flexíveis, pode-se compreender o telejornalismo como uma instituição de produção de conhecimento e construção social.

A legitimidade do jornalismo está intimamente ligada às pretensões de conhecimento e verdade. Isso é graças à sua alegação de ser capaz de oferecer cidadania ao conhecimento relevante e confiável que o jornalismo justifica sua posição como uma instituição constitutiva em uma sociedade democrática (EKSTRÖM, 2002, p.260)³.

Cumpre lembrar, ainda, o que nos ensina Arlindo Machado (2003), no capítulo "As vozes do telejornal", do livro "A televisão levada a sério", em que considera o telejornal como lugar de enunciação de sujeitos falantes, que estão ligados ao que está sendo reportado, de forma direta ou indireta (p. 104-105):

Não é sem razão que o telejornal, muitas vezes, trata não propriamente dos eventos, mas de suas próprias dificuldades em reportá-los. Quando se está numa situação de conflito particularmente perigosa, a presença física do repórter no palco dos acontecimentos e a obtenção de imagens e sons representativos do que ocorre tornamse em si mesmas problemáticas e não é raro que tais dificuldades afetem a própria substância do telejornal. (Machado, 2003, p. 105)

O teórico refere-se a situações de conflitos com exemplos de guerras, mas sua proposição não deixa de iluminar o olhar da presente pesquisa para a análise da cobertura da Pandemia da Covid-19. Como tem se efetivado essa presença do telejornalismo no palco do acontecimento durante a quarentena? A presença física no local do fato narrado pode ser sublimada pela presença atuante na contabilização dos dados e na certificação das informações científicas? São questões a serem pensadas no estudo sobre as fases da cobertura regional no Rio de Janeiro, em que a "substância do telejornal", nos termos de Machado, pode ter sofrido alterações a cada momento do avanço do vírus.

O telejornalismo precisou se reinventar de forma emergencial para levar as informações sobre a pandemia e sobre as formas de prevenção para conter a propagação do vírus. As novas condições de trabalho para as equipes demandou uma reorganização nas rotinas produtivas no telejornalismo. Pesquisa anterior, que fez uma análise sobre o impacto da pandemia nos telejornais locais da Rede Globo na Região Sudeste do país, detectou 17 novas funções e

\footnotetext{
${ }^{3}$ Tradução dos autores. No original: "The legitimacy of journalism is intimately bound up with claims to knowledge and truth. It is thanks to its claim of being able to offer the citizenry important and reliable knowledge that journalism justifies its position as a constitutive institution in a democratic society." (EKSTRÖM, 2002, p.260).
} 
competências (Reis et al., 2020), tais como repórter com máscaras, âncora com ação na bancada contra a propagação da Covid-19 e gravações de sonoras por aplicativos, entre outras.

O levantamento de novas funções e competências nos telejornais da Rede Globo na Região Sudeste (Rio de Janeiro, São Paulo, Minas Gerais e Espírito Santo) evidencia as alterações nas rotinas produtivas do telejornalismo no contexto da pandemia.

Foi interessante observar a frequência de competências que apontam para ações pedagógicas, informativas e preventivas. Assim como pode-se notar na cobertura nacional, o telejornalismo regional na pandemia teve que reinventar formas de captação, inaugurando formatos de sonoras, de enquadramentos, e até mesmo de apuração com as fontes (Reis et al., 2020, p. 283).

O presente estudo, com foco no telejornalismo do Rio de Janeiro, identificou momentos relevantes de virada no modo de produção nos telejornais regionais RJ1 e RJ2 durante a pandemia Covid-19. Seguindo a metodologia de estudo de caso (Yin, 2011), foram abertas janelas de observação a partir de fatos notórios da pandemia, tais como a primeira morte em decorrência da Covid-19 no Brasil, 100 dias de isolamento social contra propagação da doença e eleições para prefeitos e vereadores em cidades brasileiras. Em seguida, cada edição dos telejornais analisados foi observada e comparada com momentos anteriores à pandemia (referenciais aos mesmos dias e meses de 2019, ainda sem pandemia no Brasil) e a fases anteriores, de modo a identificar as alterações empreendidas, novos modos de produção e exibição, e novas funções e competências exigidas dos profissionais. As edições foram localizadas na plataforma digital de streaming de vídeos sob demanda GloboPlay, repositório pago da TV Globo, e armazenadas no âmbito da pesquisa sem possibilidade de exibição massiva por força do contrato da emissora com os assinantes da referida plataforma. As observações foram catalogadas a partir de observações de cada pesquisador, de modo a serem consideradas apenas as comuns a de pelo menos dois olhares idênticos.

Tal detalhamento permitiu analisar de modo qualitativo aproximado os modelos de produção dos telejornais estudados, identificando fases tais como improviso, desvio do padrão e pedagogia pelo exemplo nas telas, entre outras. O olhar inaugural possibilitado pela transmissão ao vivo do RJ1 e do RJ2 foi complementado, como procedimento específico, com a observação permitida no repositório consultável mediante assinatura GloboPlay. A escolha dos telejornais locais do Rio de Janeiro se justifica porque as duas edições do RJ são líderes de audiência no segmento, sendo que no início da pandemia o RJ1 atingiu a impressionante marca de 22,3 pontos de audiência segundo a mídia especializada. Ou seja, alcançou 211 mil pessoas por ponto ou 4,7 milhões ao todo no grande Rio 4 .

De acordo com a metodologia adotada, a observação direta dos comportamentos e modos operacionais permitiu a identificação de fases da cobertura telejornalística regional no Brasil durante a pandemia até setembro de 2020. A partir da análise de casos múltiplos e seus aspectos holísticos, buscou-se aqueles integrados que permitiram identificar as características

\footnotetext{
${ }^{4}$ In https://rd1.com.br/globo-dispara-na-audiencia-no-rj-com-grade-especial/ Acessado em: 20/04/2020.
} 
de cada fase, vistos aqui como pontos de observação em janelas, nas edições selecionadas a cada mês.

\section{AS FASES DA COBERTURA DA PANDEMIA NO RJ1 E NO RJ2}

A escolha de analisar os telejornais locais "RJ1" e "RJ2" se deu pela compreensão de que esses programas representam praças de referência por contarem principalmente com 0 abastecimento da equipe do Jornal Nacional, além da produção ocorrer na mesma redação, o que facilita o trânsito de informações mais relevantes do Estado do Rio. Os noticiários "RJ1" e o "RJ2" são telejornais locais, com periodicidade de segunda a sábado e abastecem a região metropolitana do Rio de Janeiro, além dos municípios de Niterói e São Gonçalo. O noticiário "RJ - 1a edição" (RJ1) tem duração média de 50 minutos e é apresentado pela jornalista Mariana Gross. Já o "RJ - 2a edição" (RJ2) prevê um tempo de 20 minutos de produção e tem como apresentadora a jornalista Ana Luísa Guimarães.

A partir das análises das 18 edições, foi possível observar uma reorganização nos modos de produção e transmissão da notícia. O primeiro caso de contágio da Covid-19 no Estado do Rio foi anunciado no dia 05 de março de 2020. De lá pra cá os noticiários passaram a ser temáticos, principalmente com o anúncio da primeira morte no dia 19 de março. Um dado peculiar na cobertura do anúncio do primeiro óbito por Covid-19 foi quando o apresentador Edimilson Ávila afirmou que ele e a jornalista Gabriela de Palhano estavam fazendo contagem de dados sobre casos e mortes de Covid-19 para construir uma curva própria regional. Desse modo, o telejornal assume nova competência na função de mediador social e, lançando mão do jornalismo de dados (BARBOSA, 2007), passa a ser intérprete de dados estatísticos sobre a doença, angariando cada vez mais credibilidade. Soma-se isso ao fato da restrição do governo federal de dar acesso aos dados consolidados oficiais da pandemia, não cumprindo com as normas de transparência. Vale destacar que em 08 de junho de 2020, em uma ação inédita, veículos de comunicação como G1, O Globo, Extra, Estadão, Folha e UOL criaram um consórcio para trabalhar de forma colaborativa na contagem dos dados sobre a pandemia ${ }^{5}$.

Após as análise das edições, a pesquisa detectou fases da cobertura da Covid-19, com marcas que apontam para uma série de fatores que atravessam a produção telejornalística, como, por exemplo, mudanças na rotinas produtivas, novas funções demandadas das equipes, tensionamentos sobre divulgação e apuração de dados certificados, critérios de noticiabilidade durante a pandemia e busca por formas de narrar a morte e o medo, em uma construção narrativa da pandemia que passou por etapas, no diálogo com a sociedade. Foram detectadas nove fases, explicadas a seguir.

Tabela 1

Fases da cobertura da Pandemia no RJ1 e no RJ 2

\begin{tabular}{|l|l|l|}
\hline Datas das Edições & Acontecimentos & Fases da Cobertura \\
\hline 19 de março de 2020 & Primeira morte & Fase do improviso \\
\hline
\end{tabular}

\footnotetext{
${ }^{5}$ In https://www1.folha.uol.com.br/equilibrioesaude/2020/06/veiculos-de-comunicacao-formamparceria-para-dar-transparencia-a-dados-de-covid-19.shtml. Acessado em: 02/08/2020.
} 


\begin{tabular}{|c|c|c|}
\hline 01 de abril de 2020 & $\begin{array}{l}\text { Primeiro mês da pandemia (auxílio } \\
\text { emergencial) }\end{array}$ & Fase de apostas \\
\hline 05 de maio de 2020 & Adoção do uso de máscaras & Fase do exemplo \\
\hline 12 de junho de 2020 & Dia dos Namorados & Fase do desvio do padrão \\
\hline 25 de julho de 2020 & $\begin{array}{l}100 \text { dias de quarentena } \\
\text { Dia da avó; Dia da mulher negra }\end{array}$ & Fase do jornalista multitarefa \\
\hline 08 de agosto de 2020 & 100 mil mortes & $\begin{array}{l}\text { Fase do jornalismo ultra- } \\
\text { certificador }\end{array}$ \\
\hline 22 de setembro de 2020 & $\begin{array}{l}\text { Pós-feriado de } 7 \text { de setembro } \\
\text { Início da primavera; Chuva }\end{array}$ & Fase da pandemia naturalizada \\
\hline 14 de outubro de 2020 & $\begin{array}{l}\text { Eleições municipais no Brasil } \\
\text { (prefeitos e vereadores), violência }\end{array}$ & $\begin{array}{l}\text { Fase da pandemia naturalizada } \\
\text { estendida }\end{array}$ \\
\hline 17 de novembro de 2020 & $\begin{array}{l}\text { Segundo turno das eleições, festas de } \\
\text { fim de ano, aumento do número de } \\
\text { casos e mortes }\end{array}$ & Fase do telejornalismo gangorra \\
\hline
\end{tabular}

Fonte: elaboração própria.

Na chamada "fase do improviso" ocorreu um reforço discursivo dos jornalistas, reafirmando a todo instante que eles estavam tomando as providências necessárias para a segurança da equipe, com distanciamento social e evitando aglomeração, até mesmo dentro da redação. A adoção de microfones distintos (sendo um para a fonte) passou a ser uma prática, causando estranhamento no enquadramento captado pelo repórter cinematográfico. É nesse momento que ocorre o aproveitamento de equipes do núcleo de esporte e de entretenimento, já que os noticiários passam a ter mais tempo de duração desde a suspeita da primeira morte em 17 de março de 2020. Os telejornais regionais do Rio de Janeiro ficaram temáticos, incluíram especialistas no estúdio para responder dúvidas da população sobre o coronavírus, estabeleceram uma relação de confiança e dependência das fontes, que precisam ceder vídeos com depoimentos seguindo moldes técnicos mais próximos da natureza televisiva. Por conta da diminuição de equipes e restrições sociais, o uso do grafismo ganhou espaço nas peças televisuais para compensar a falta de imagens.

Nota-se, ainda, uma ampliação significativa das entradas ao vivo, bem como os comentários no estúdio entre apresentadores com o apoio do grafismo e do telão, reforçando a polifonia incluída nos telejornais como tentativa de mediação simbólica entre eventos e espectadores dos sujeitos falantes (Machado, 2003). Ainda é possível perceber que os apresentadores e repórteres, mesmo ainda sem saber como agir diante da pandemia, tentavam transmitir uma segurança discursiva ao reforçar os cuidados necessários para evitar o contágio do vírus. Dessa forma, agiam como operadores didáticos, buscando audiência por meio da segurança e lugar 
de referência, cumprindo com o jornalismo como forma de conhecimento e, portanto, exercendo a função pedagógica do telejornal (Vizeu e Cerqueira, 2019b).

A "fase de apostas" mostra um esforço para fazer uma cobertura temática depois de duas semanas de isolamento. Iniciou no RJ1 com tentativas, erros e acertos para noticiar um tema inesperado e, ainda, cheio de imprevisibilidades. Foram observados aspectos como um reforço da fase inicial ("fase do improviso") do esforço de mostrar que o telejornal não está submetido apenas aos números oficiais e produz a contagem própria do número de vítimas da Covid-19, como anteriormente anunciado pelo apresentador Edimilson Ávila; aumento de aparições do repórter em diferentes enquadramentos, bem como das sonoras e artes do Google Earth para suprir a carência de imagens; uso de áudio apenas com simulador de frequência vocal; a ausência do local da passagem nos créditos, pois muitas reportagens precisaram ser fechadas dentro da emissora; reafirmação na imprensa como lugar de referência (a família da vítima da primeira morte no município de São Gonçalo ficou sabendo do acontecimento pela imprensa); uso de imagens mais subjetivas nas peças e na escalada; aumento do tempo de estúdio para suprir dúvidas que chegavam inclusive pelo telefone celular do apresentador. Por outro lado, foram evidenciadas edições mais apressadas por conta do deadline curto, na medida em que existe uma dependência das fontes por falta de tanta mobilidade das equipes; repetição de personagens nas peças e aproveitamento de conteúdos; produtores e editores acumulando funções; entrevistados utilizando máscaras antes dos repórteres e uma aposta não bem sucedida de entradas ao vivo para assunto factual com equipe do SportTV.

Um caso bastante peculiar é do repórter Pedro Figueiredo que trabalhou no esquema de home office depois que o marido dele, o repórter Erick Rianelli, testou positivo para Covid-19 e foi afastado. Pedro continuou trabalhando de casa e estava assintomático. Ainda na "fase de apostas", na edição do "RJ2", notou-se um esforço para incluir temas mais leves já na escalada do telejornal (como o exemplo da repórter Carol Barcellos fazendo abdominal em casa gravada pela própria filha de 8 anos), mantém a falta de localização nas passagens; dão destaque para as subnotificações ao mesmo tempo que sugerem uma velocidade mais lenta de contaminação por escuta de especialistas e reportagem sobre desaceleração de insuficiência respiratória.

Durante a observação, uma mudança significativa: na edição do "RJ1" ainda não se identificava as vítimas. No mesmo dia, na edição do "RJ2", várias vítimas mortas por Covid-19 foram identificadas em uma reportagem que traçava o perfil de pacientes com o novo coronavírus. Na mesma edição foi possível observar uma disputa de temas entre economia e saúde. Naquele momento, existia uma ideia de que a pandemia seria passageira, o que pode justificar os diversos tons nas inúmeras tentativas de coberturas, como por exemplo, a reportagem do "Desafio na Quarentena" com tons leves, mostrando, como citado, a repórter Carol Barcellos fazendo exercício físico em casa. Nesse contexto, nota-se que o telejornal tenta trabalhar com estratégias comunicacionais para atrair o público e angariar credibilidade durante a pandemia, utilizando o "entretenimento como valor-notícia fundamental" (Aguiar, 2008).

A "fase do exemplo" é marcada no dia 05 de maio, após o anúncio feito na véspera pelo "Jornal Nacional" sobre a adoção do uso de máscaras pelas equipes de reportagens. Os telejornais regionais seguiram o mesmo padrão marcando. Apesar do desconforto e certo nível de improviso na fala com o uso de máscara, todos os repórteres começaram a usar o acessório que se mantém obrigatório e indispensável até os dias de hoje, depois de mais de cinco meses 
de cobertura. Para além do fator da proteção de contaminação, o uso da máscara pela equipe de reportagem representa uma interpretação semiótica de segurança para os telespectadores.

A fase do "desvio de padrão" coincide com a flexibilização do isolamento autorizado pelos governos municipal e estadual. A escalada do noticiário mostra que, pela primeira vez, a fila para os leitos está praticamente zerada nos sistemas de regulação hospitalar. O telejornal "RJ1" é composto por sonoras soltas com cabeças chamadas pelo apresentador, excesso de falas do locutor ao vivo aproveitando "cacos" para a construção do noticiário, colagens de sonoras seguidas sem imagens, aproveitamento de conteúdos do noticiário anterior - o "Bom dia Rio" e do "Desenrola Rio"6, programa de podcast do apresentador Edimilson Ávila, em uma perspectiva transmídia de fazer circular os conteúdos produzidos na pandemia, inclusão de reportagens que podem ser vista como publicidade nativa (Wybenga, 2013), ou seja, reportagens informativas de interesse comercial implícito - a exemplo do quadro Solidariedade do "Jornal Nacional". Essa edição apresenta temas mais leves como festas em hospital para pacientes com Covid-19, artistas "vendendo" lives do Dia dos Namorados, uma reportagem de mais de 15 minutos sobre o Dia dos Namorados com a participação do repórter no carro de mensagem e aproveitamento de reportagens nacionais, além das entradas ao vivo mais longas. Outra ação de desvio identificada foi a junção de duas repórteres no mesmo VT, ou seja, o off passava para outra voz em uma tentativa de não desperdiçar material semelhante e mostrar pluralidade de equipe enquanto o quadro ainda era de desfalque. Durante as duas edições foi possível observar um tom mais tênue, tentando incluir outros temas no agendamento do noticiário do Rio de Janeiro.

Os cem dias de quarentena, no dia 25 de julho, marcaram a "fase do jornalista multitarefa". Com privação do contato social estendida e sem perspectivas para o fim do isolamento, os telejornais "RJ1" e "RJ2" passaram a abordar outras pautas como cultura, dia das avós, dia da mulher negra e a cobertura deixou de ser temática. As peças também estavam maiores. Notase uma redução de equipes (apresentadores e repórteres se repetem nas edições) e a manutenção do aproveitamento de outros setores, sobretudo do esporte com a participação da apresentadora e repórter Carol Barcellos no "RJ1" e da repórter Lizandra Trindade para reportagem factual. Os jornalistas precisaram se adaptar às novas formas de produção e transmissão da notícia, numa perspectiva de "multieditoria". Ou seja, a imprevisibilidade da pandemia trouxe a necessidade de um rodízio de tarefas e novas funções nas redações (Thomé e Reis, 2019).

A chamada "fase do jornalismo ultra-certificador" teve como marcação as 100 mil mortes no Rio de Janeiro. Um protesto em Copacabana marcou a data e teve a cobertura de uma equipe da GloboNews, com a jornalista Narayanna Borges, indicando a permanência do rodízio entre as equipes. Tanto a repórter quanto a apresentadora Mônica Teixeira reforçaram que os números de casos e mortes da Covid-19 são contados a partir de um consórcio da imprensa, criado desde junho e 2020. Esse é um marco na imprensa, que de forma inédita se reuniu para produzir os próprios dados. Vale lembrar que no início da quarentena, em março, ainda na "fase do improviso" o apresentador Edmilson Ávila afirmou que estava fazendo a contagem diária de vítimas da Covid-19 junto com a então editora de texto Gabriela de Palhano. Essas novas funções observadas indicam um mergulho no jornalismo de dados, e franco crescimento

${ }^{6}$ In: https://audioglobo.globo.com/g1/podcast/feed/704/desenrola-rio. Acessado em: 11/10/2020. 
no jornalismo da web e impresso, garantindo ao profissional um papel ampliado como mediador de dados.

A "fase da pandemia naturalizada" é a mais recente e ocorreu em setembro, no início da primavera, com as duas edições temáticas por conta das fortes chuvas que atingiram o Rio de Janeiro. "O RJ" que tinha aumentado o tempo de produção do noticiário por conta da pandemia voltou a ter em média 1 hora de duração.

As edições analisadas em setembro mostram que os telejornais não mencionaram sobre os números da Covid-19. A palavra pandemia foi dita apenas quando o telejornal já ultrapassava mais da metade do tempo de produção, dentro do off de um único VT exibido, mas sem o contexto de informação de vítimas. Vale lembrar que a reportagem gravada dizia respeito a prisão de um casal de golpistas, ou seja, perderia o valor-notícia caso não fosse divulgada. Outro aspecto curioso é que a escalada foi suprimida e as entradas ao vivo ganharam espaço. Aliás, quase toda a edição do RJ1 foi feita por longas entradas ao vivo com um GC (gerador de caracteres) único: "CHOVE SEM PARAR: Primavera começa com chuva, frio e vários bolsões d'água pela cidade"7. O vai e vem do ao vivo com o elemento "improviso" e com chamadas de trânsito pelas câmeras da CET Rio, demonstrava que a técnica de preenchimento do telejornal com entradas ao vivo e de forma temática sobre chuva, assunto de interesse público, sem dúvida, suprimiu o assunto da pandemia. Importante destacar que os números da Covid-19 no dia totalizavam 17.798 mortes e 253.756 casos da doença ${ }^{8}$. Tais números sequer foram atualizados nas duas edições. O país indicava alta no número de mortes em sete estados,

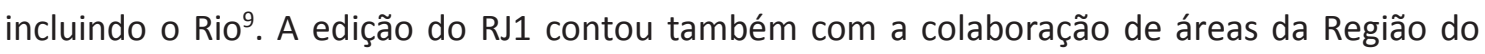
Lagos. Nessa fase, as reportagens já não contam tanto com a colaboração das fontes na cessão de vídeos e depoimentos e nem com tanta utilização de videoconferência. Percebe-se que as equipes já estão mais nas ruas e permanecem com o uso das máscaras.

A edição do "RJ2" também foi temática sobre a chuva com muitas entradas ao vivo, mas com VT fechados aproveitando o material anterior do RJ1. A escalada foi feita com imagens de enchente e trouxe sobe som de vários moradores atingidos pela chuva em off, ou seja, eles não aparecem falando. Um fato curioso é a manutenção da divisão de VT com duas repórteres.

Além dos números da pandemia não serem mencionados e nem atualizados, outro aspecto que mostra uma naturalização da pandemia, que marca a fase em questão, por conta dos próprios telejornais e que, portanto, ajuda a construir socialmente a realidade, é a exibição de entrevistados sem máscara e utilizando o mesmo microfone do repórter. Ou seja, todo o cuidado explicitado no início com a pandemia não é mais realidade para quem assiste ao "RJ1" ou "RJ2". Assim, é relevante refletir sobre qual produção de sentido é gerada para o telespectador quando o telejornal, sendo um lugar de referência e segurança (Vizeu e Cerqueira, 2019a), relaxa os próprios operadores didáticos (Idem), demonstrando um afrouxamento com a pandemia e com as restrições de distanciamento social, criando uma

\footnotetext{
${ }^{7}$ In:https://globoplay.globo.com/v/8876569/ Acessado em: 02/10/2020.

8 In https://g1.globo.com/rj/rio-de-janeiro/noticia/2020/09/22/rj-chega-a-17798-mortes-e-a-253756casos-de-covid-19.ghtml. Acessado em: 12/10/2020.

${ }^{9}$ In https://g1.globo.com/bemestar/coronavirus/noticia/2020/09/22/casos-e-mortes-por-coronavirusno-brasil-em-22-de-setembro-segundo-consorcio-de-veiculos-de-imprensa.ghtml. Acessado em: $12 / 10 / 2020$.
} 
construção de mundo que atravessa a opinião pública e interfere nos modos de ação e comportamento na sociedade.

A "fase da pandemia naturalizada estendida" coincide com a reta final da campanha eleitoral para escolha de prefeitos e vereadores nas cidades brasileiras, ocorrida em 15 de outubro de 2020. Com foco nas eleições e critérios de noticiabilidade voltados para saúde e Covid, apontando lotação nos transportes públicos como algo preocupante. Ocorre, no entanto, um relaxando dos cuidados com algumas reportagens abrindo mão do uso de dois microfones e do distanciamento para evitar a propagação da doença, mas o uso de máscaras por profissionais e entrevistados se mantém como símbolo semiótico do noticiário em plena pandemia, mesmo que diante dos claros sinais de redução do total de mortes e contágios.

Já a "fase do telejornalismo gangorra" compreende a campanha no segundo turno das eleições municipais na cidade do Rio de Janeiro e nos municípios de São Gonçalo (no Grande Rio), São João de Meriti (Baixada Fluminense), Campos e Petrópolis, ambos no interior do estado do Rio. Total de casos fica estável, com números da pandemia sendo exibidos por videografismos em estúdio, mas já se identifica indícios da nova onda da pandemia na capital. Há mais imagens feitas em reportagens externas, exibidas entre participações de repórteres "ao vivo", formato que subiu em número nessa fase que se estende até as festas de fim de ano. Reportagens especiais, com maior duração, são introduzidas, enquanto conteúdos denunciando aglomerações nas festividades passam aos poucos a ganhar mais espaço no noticiário, já indicando a possibilidade de uma nova onda pandêmica no início de $2021^{10}$.

\section{CONSIDERAÇÕES FINAIS}

A partir da presente análise, foi possível identificar nove fases da cobertura do telejornalismo regional do Rio durante a pandemia da Covid-19 entre março e dezembro de 2020. Observando edições do RJ1 e do RJ2 nesses meses, percebemos uma fase inicial, classificada aqui como "Do improviso", na qual o telejornal reproduziu nas telas a situação de improvisação dos modos de produção em meio à implantação do isolamento social e dos primeiros casos da doença e de mortes em função do coronavírus. A esse momento inaugural, seguiu-se outro, o "De apostas", no qual novas competências e novos modos narrativos foram implantados de modo a garantir a segurança das equipes jornalísticas e manter o papel informativo dos telejornais, papel relevante diante dos desencontros de dados oficiais sobre propagação e gravidade da doença fatal.

O uso das máscaras nos telejornais regionais, a partir de 5 de maio de 2020, foi uma novidade na rotina produtiva das equipes de externa, sobretudo para repórteres, que precisaram adaptar a locução, e também para os telespectadores, que passaram a ter o exemplo de prevenção nas telas, de forma pedagógica, informação passada de forma subliminar, de que a máscara é necessária, configurando a "fase do exemplo".

Em período próximo ao Dia dos Namorados, ocorreu um inesperado "desvio do padrão" do telejornal, caracterizado aqui como uma fase em que a flexibilização do isolamento autorizado

\footnotetext{
${ }^{10}$ No Brasil, a pandemia Covid-19 havia causado 207 mil mortes até 14 de janeiro de 2021, dentro de um universo total de 8,3 milhões de casos desde fevereiro de 2020. O noticiário já indicaria uma nova onda pandêmica, com aumento do número de casos e mortes após as festividades do Natal e do Ano Novo. No Rio totalizando 473 mil casos e 27 mil mortes, a doença registra nova alta.
} 
por autoridades sanitárias marcou mudanças bruscas nos noticiários. A essa fase, seguiu-se a do "jornalista multitarefa", com evidente redução das equipes. A demanda por atuação em multitarefa já vinha marcando as produções dos telejornais, mas nessa fase fica mais evidenciada no resultado nas telas.

Com o aumento do uso do jornalismo de dados nas edições, estimulado pela recusa governamental de fornecer dados oficiais consolidados, o telejornal inaugurou a "fase do jornalismo ultra-certificador", ampliando seu papel de certificação e prometendo à audiência a consolidação de dados regionais, com esforço em prol da credibilidade do noticiário sobre os cuidados necessários para conter a doença.

Por fim, identificou-se uma fase na qual a pandemia deixa de ser tema central do noticiário, que abre espaço para outros assuntos a partir dos chamados critérios gerais de noticiabilidade. Classificada como "Fase da pandemia naturalizada", mantém, no entanto, externas com repórteres usando máscaras, sonoras por meio de aplicativos e um modo de produção ainda cuidadoso com os riscos de propagação da doença.

Com a aproximação das eleições municipais no Rio de Janeiro, as pautas apresentaram gradientes que basicamente contemplavam saúde e política para falar sobre a pandemia da Covid-19, com foco no protagonismo da viabilização política da vacina. Assuntos como o segundo turno das eleições, o aumento dos casos e mortes, a lotação nos leitos dos hospitais e a aproximação com as festas de fim de ano serviram de indicativos suficientes para a classificação do telejornalismo gangorra. Notou-se um movimento cíclico de cobertura, reforçando que o telejornalismo traz como característica fundamental esse dimensão mutável, reconfigurando os modos de fazer jornalismo audiovisual. Nesse sentido, a longevidade do telejornalismo está justamente nesse poder camaleônico de rupturas, permanências e adaptabilidades ao tempo.

Tais fases poderão ser seguidas por outras no telejornalismo do Rio de Janeiro, foco deste trabalho, uma vez que a pandemia completou um ano ainda com riscos de contágio elevados no país, exigindo medidas de isolamento. $O$ recorte temporal aqui proposto dá abertura para futuros olhares dos autores que, em estudo conjunto, a partir de diferentes instituições de ensino, observam novas funções e competências desempenhadas por jornalistas de TV durante a pandemia, os modos de produção e as estratégias narrativas dos telejornais da região Sudeste de modo a contribuir para futuros estudos nesse campo, sobretudo após a pandemia, e para história e o ensino do telejornalismo no Brasil.

\section{Referências}

Aguiar, L. A. (2008). Entretenimento: valor-notícia fundamental. Estudos em Jornalismo e Mídia. UFSC.

Barbosa, S. (2007). Jornalismo Digital de Terceira Geração. LabCom.

Becker, B. (2016). Televisão e Telejornalismo: Transições. Editora Estação das Letras e Cores.

Bolaño, C.; Melo, P. V. (2015, 4 a 7 de setembro). Luz, câmera, concentração: 50 anos da Rede Globo e a hegemonia no Mercado Brasileiro de Televisão. Anais do 38 Congresso Brasileiro da Comunicação. Intercom. 
Coutinho, I.; Emerim, C. (2019). Lugares, espaços, telas e reconhecimento: o local do telejornalismo na contemporaneidade. Em: I. Coutinho, C. Emerim (orgs.). Telejornalismo local: teorias, conceitos e reflexões. Insular.

Ekström, M (2002). Epistemologies of TV Journalism: a Theoretical Framework. Sage Publications.

Machado, A. (2003). A televisão levada a sério. Editora Senac São Paulo.

Piccinin, F.; SOSTER, D.A. (2012). Da anatomia do telejornal midiatizado: metamorfoses e narrativas múltiplas. Brazilian Journalism Research.

Reis, M. A. ; Thomé, C.; Silva, E. M.. ; Andrade, A. P. G.; Miranda, P. (2020). Novas funções e competências no telejornalismo regional frente à Covid-19. Em C. Emerim, C.; A. Pereira; I. Coutinho. (Orgs.) A (re)invenção do Telejornalismo em tempos de pandemia. Insular.

Silva, E. M. (2015, 4 a 6 de novembro). Na tela da TV Tupi: marcas históricas do telejornalismo brasileiro. [Apresentação de trabalho]. Anais do 13 Encontro Nacional de Pesquisadores em Jornalismo. SBPJor.

Silva, E. M (2018). Fases do Telejornalismo: uma proposta epistemológica. Em C. Emerim; I. Coutinho; C. Finger (Orgs.). Epistemologias do telejornalismo brasileiro. Insular.

Silva, E. M.. ; Alves, Y. M. (2016, 5 a 9 de setembro) Telejornalismo Expandido: A Apropriação de Redes Sociais e Aplicativos pelo Jornalismo Televisivo. [Apresentação de trabalho]. Anais do 39o Congresso Brasileiro de Ciências da Comunicação. Intercom.

Silva, E. M.. ; Alves, Y. M. (2017, 4 a 9 de setembro). Bases epistemológicas do Telejornalismo Brasileiro: do Telejornalismo Falado ao Telejornalismo Expandido. [Apresentação de trabalho]. Anais do 40ํㅡㄹ Congresso Brasileiro de Ciências da Comunicação. Intercom.

Thomé, C.; Reis, M. A. (2019a). Novas funções e competências no telejornalismo regional. Em Coutinho, I. C. Emerim. (org). Telejornalismo local: teorias, conceitos e reflexões. Editora Insular.

Thomé, C.; Reis, M. A. (2019b. 2 a 7 de setembro). Espelhamento da rede no telejornalismo regional: novas funções no contexto de multitarefas. [Apresentação de trabalho]. Anais do 42응 Congresso Brasileiro de Ciências da Comunicação. Intercom

Thomé, C.; Piccinin, F. Reis, M. A. (2020). Anatomias narrativas do telejornalismo contemporâneo e seus elementos certificadores. Em C.Emerim, C.; A. Pereira,; I. Coutinho (Org). Telejornalismo 70 anos - o sentido das e nas telas. Ed. Insular.

Vizeu, A.; Cerqueira, L. (2019a) O "lugar de referência" do telejornalismo local: o papel dos saberes, dos dispositivos didáticos e da temporalidade. Em I. Coutinho; C. Emerim (org). Telejornalismo local: teorias, conceitos e reflexões. Ed. Insular.

Vizeu, A.; Cerqueira, L. (2019b). Os saberes da pedagogia no telejornalismo: Paulo Freire e a prática jornalística. Revista FAMECOS. PUC-RS.

Wybenga, E. (2013). The editorial age. Adfo Groep3.

Yin, R. (2011). Estudo de caso - planejamento e métodos. Bookman. 


\section{Semblanza de los autores}

Cláudia Thomé é jornalista e professora da Faculdade de Comunicação e do PPGCOM da Universidade Federal de Juiz de Fora (UFJF), líder do Grupo de Pesquisa Narrativas Midiáticas e Dialogias (UFJF/CNPq). Mestre em Comunicação e Cultura pela ECO/UFRJ, é doutora em Ciência da Literatura pela Faculdade de Letras da UFRJ. Integra a Rede de Pesquisadores em Telejornalismo no Brasil (Rede Telejor) e atualmente é vice-coordenadora do GP Telejornalismo, do Intercom.

Edna de Mello Silva é Jornalista e licenciada em Letras pela Universidade São Judas Tadeu, mestre e doutora em Ciências da Comunicação pela ECA-USP. Possui pós- doutorado com pesquisa sobre história do telejornalismo pela UFRJ (2015). Atualmente é docente do Curso Superior de Tecnologia em Design Educacional da Universidade Federal de São Paulo (UNIFESP) e docente colaboradora do PPGCOM/UFT. Integra a Rede de Pesquisadores em Telejornalismo no Brasil (Rede Telejor). É líder do Grupo de Pesquisa Comunicação, Design e Tecnologias Digitais (CoDe/CNPq/Unifesp).

Marco Aurelio Reis é jornalista e professor do curso de Jornalismo da Unesa-RJ, onde é pesquisador bolsista do Programa de Pesquisa e Produtividade e coordenador da graduação em Produção Audiovisual (Campus João Uchôa). Vice-líder do Grupo de Pesquisa Narrativas Midiáticas e Dialogias (UFJF/CNPq) e professor colaborador do PPGCOM/UFJF. Integra a Rede de Pesquisadores em Telejornalismo no Brasil (Rede Telejor). Graduado pela Escola de Comunicação da UFRJ, é mestre e doutor pela Faculdade de Letras da UFRJ.

Ana Paula Goulart de Andrade é jornalista, pesquisadora e professora no Ensino Superior. É doutoranda e mestre pelo Programa de Pós-graduação em Comunicação Social da PUC-Rio, especialista em Telejornalismo e integra a Rede de Pesquisadores em Telejornalismo no Brasil (Rede Telejor). Atualmente é professora dos Cursos de Jornalismo (UFRJ e Facha), coordenadora de Pós-Graduação (Facha) e membro da diretoria da ABEJ - Associação Brasileira de Ensino do Jornalismo 